\title{
A Reutilização da Água Cinza em Habitação de Interesse Social Através de Sistemas Produto+Serviço
}

\author{
The reuse of greywater in housing of social interest through product + service \\ systems
}

ANDREAZZA BUSSI, Luize; Pós-Graduada; Pontifícia Universidade Católica do Paraná

luize@arqlb.com.br; luizeandreazza@gmail.com

LEMOS LIMA, Rafaela. Graduada; Universidade Federal do Paraná

rafaelalemos.dgn@gmail.com

ZANELATTO WORMSBECHER, Carolina. Pós-Graduanda; Universidade Federal do Paraná

carolzanelatto@gmail.com

\section{Resumo}

O presente artigo é um dos resultados do projeto LeNsin ${ }^{1}$, que ocorreu no mês de março de 2018, na UFPR e teve como principal objetivo o desenvolvimento de um sistema de Produto+Serviço (PSS) com foco na problemática da água, enquanto recurso e escassez, para habitações de interesse social. Desta maneira, este artigo visa apresentar o desenvolvimento do projeto de Produto+Serviço (PSS) em questão e suas etapas, a partir da Metodologia de Design Science e MEPSS. O projeto em questão trata do reuso de água cinza: durante seu desenvolvimento, foi possível investigar questões de consumo de água bem como possíveis formas de reuso. Assim, o projeto objetiva evitar, não apenas que a escassez de água se torne irremediável, mas também a possibilidade de se extrair deste momento soluções mais efetivas, duradouras e, por consequência, mais sustentáveis.

Palavras Chave: PSS; design para sustentabilidade; reuso de água; água cinza.

\begin{abstract}
This article is one of the results of the LeNsin project, which occurred in March, 2018, at UFPR. Having as main objective, the development of a Product + Service (PSS) system focused on the water problem: Resource and scarcity for housing of social interest. Specifically, the project of this article deals with the reuse of greywater: during the program, it was possible to investigate, besides the questions of water consumption, how to use of possible forms of reuse (gray water). In order to avoid not only the scarcity of water becoming irremediable, but also the possibility of extracting from this moment, solutions that are more effective, longer lasting and therefore more sustainable. Therefore, this article explores, through the practical experience of creating a Product + Service System (PSS), that sustainable solutions are, in addition, necessary, possible.
\end{abstract}

\footnotetext{
${ }^{1}$ LeNsin: the Learning Network on Sustainability International. Projeto Financiado pelo programa ERASMUS+ Comissão Europeia voltado ao desenvolvimento curricular e difusão global do ensino sobre Sistemas Produto + Serviço Sustentáveis e Economia Distribuída. Disponível em: <http://www.lens-international.org>
} 
Keywords: water; greywater; reuse; PSS; sustainability.

\section{Introdução}

\subsection{Cenários}

A situação e as alterações climáticas que o planeta terra vivencia são, a cada dia, mais evidentes. No mês de março, atenções voltam-se para o tema "Água": sua presença e sua escassez. Neste ano de 2018, o encontro mundial sobre o tema aconteceu em Brasília e decretou que de 2018 a 2028 será a década da água. A previsão da Organização das Nações Unidas (ONU, 2017) é que, até 2030, a demanda por água no mundo aumente em $50 \%$. Por outro lado, a porcentagem de esgoto produzida e sem tratamento beira a margem de mais de $80 \%$. Ainda segundo relatório da ONU, o custo total da insegurança hídrica para a economia mundial é estimado em US\$ 500 bilhões anuais. Incluindo o impacto ambiental, esse valor pode chegar a 1\% do Produto Interno Bruto (PIB) mundial (SADOFF ET AL., 2015). No Brasil, segundo o IBGE, 85,8\% dos estados e municípios têm acesso ao abastecimento de água e apenas 65,9\% dos domicílios possuem sistema de esgotamento sanitário. O consumo médio de água no país é de 154,1 litros por habitante ao dia, uma queda de 4,1\% em relação à média dos anos de 2013, 2014 e 2015.

Os dados acima descritos são fortes indícios para que a preocupação com o abastecimento, saneamento, gastos nacionais na viabilização de sistemas de infraestrutura e qualidade de vida da população brasileira, aumenta à medida que as oscilações climáticas tornam reais números antes projetados.

\section{2 Água, Água Cinza e Reuso de Água: Definições \& Características}

A água, por definição, é um recurso natural que pode ser encontrada tanto no estado líquido, como sólido e gasoso. Solvente universal, não se encontra em estado de pureza absoluta e sim com a presença de elementos contaminantes como por exemplo, matérias orgânicas dissolvidas, sais minerais, micro-organismos e sólidos em suspensão.

Para avaliação das suas condições de potabilidade analisam-se parâmetros físicos como presença de sólidos, cor, temperatura, odor e turbidez; parâmetros químicos como pH e parâmetros biológicos como vírus, bactérias (como os coliformes), protozoários e helmintos. Por "Águas Cinzas" entende-se águas residuais e provenientes dos lavatórios, chuveiros, tanques, máquinas de lavar roupas e louças, embora neste item não haja consenso internacional, já que alguns autores não consideram o efluente proveniente de cozinhas como água cinza, devido à presença de óleos e gorduras (SOTHE, 2013).

O "reuso da água" pode ser aqui explicado como a reutilização da água que após sofrer tratamento adequado, destina-se a diferentes propósitos, com o objetivo de se preservarem os recursos hídricos existentes, diminuir o consumo de água potável para fins menos nobres e contribui para a sustentabilidade hídrica das cidades. Para que esse reuso seja seguro, é crucial a verificação da análise da qualidade das águas de abastecimento e do tipo de rede de distribuição. De acordo com a NBR 13696/1997, as águas cinzas classificam-se em quatro categorias de reuso:

- Classe 1: Destinadas a descarga de bacias sanitárias, lavagem de pisos, fins ornamentais (chafariz, espelho d'água), lavagem de roupas e veículos;

- Classe 2: Aplicadas nas várias fases associadas à construção civil como a lavagem de 
agregados e preparação de concreto;

- Classe 3: Destinadas à irrigação de áreas verdes e rega de jardins;

- Classe 4: Uso preponderante no resfriamento de equipamentos de ar condicionado

Ainda de acordo com o Relatório da ONU sobre o Desenvolvimento dos Recursos Hídricos (ONU, 2017) ainda é pouca a atenção dada a reutilização de águas residuais como estratégia na solução e economia de água. Se, a análise de reutilização de água ganhasse um olhar mais atento, poderiam evitar-se impactos negativos sobre a sustentabilidade do abastecimento de água, a saúde humana, a economia e o meio ambiente. A fim de evitar resistências públicas frutos da falta de informação, de aspectos culturais ou mesmo da falta de confiança com relação aos riscos à saúde humana, identifica-se a necessidade da realização de um programa de educação e de um sistema que considere produtos e serviços confiáveis para obtenção dos resultados positivos no reuso de águas cinzas.

Apesar da água ser um recurso acessível e de baixo custo em determinadas regiões como por exemplo a região Sul do país, em outras regiões como as cobertas pela caatinga em quase 800 mil km², sua falta obriga milhares de pessoas a percorrerem quilômetros para coletarem-na dos açudes. Diante do grave quadro e das previsões de crescente urbanização, faz-se necessário a mudança de hábitos de consumo e utilização da água. Repensar formas de utilização de águas residuais, poderiam contribuir significativamente para economia deste recurso natural.

\title{
1.3 Design e Sustentabilidade: PSS
}

O presente artigo objetiva a aplicação do PSS na resolução do uso racional da água no contexto da habitação de interesse social. Nesse contexto, analisar-se-á não apenas o recurso "água" em si, e sim suas questões de abastecimento, consumo, armazenamento e possível reutilização. Segundo Manzini (2006) apud Guimarães e Wagner (2010):

\begin{abstract}
“...a sustentabilidade exige inovações sistêmicas radicais baseadas numa redução drástica do consumo e numa nova ideia de bem-estar, cujos valores regeneram o tecido social, econômico e ambiental. O designer deve então criar uma ponte entre as condições externas e as condições internas que possibilitam a mudança, através de experiências locais que mostrem conhecimentos e possibilidades inovadoras. Segundo esse autor não há mudança sistêmica se ela não estiver preparada numa escala local (práticas locais, cotidianas). A mudança sistêmica ocorre em termos de um processo de aprendizagem social que exige uma aprendizagem, a partir dos resultados, para reorientar os novos passos e maximizar as possibilidades de uma ação consciente da realidade e dos resultados consequentes a essa ação". (MANZINI, 2006, p.02 apud GUIMARÃES e WAGNER, 2010)
\end{abstract}

No que toca a obtenção de um estado de "bem-estar", é importante promover e assumir mudanças de comportamentos e identificação com padrões de consumo intrinsecamente insustentável de recursos ambientais. Segundo Manzini, (2008):

\footnotetext{
“...nossa aspiração comum para o Design é, ou deveria ser, criar condições para que isso (mudanças) aconteçam. Não como uma necessidade, mas sim, como escolha. Que aconteça pela força de atração exercida pelas novas oportunidades e ideias de bem-estar e não sob pressão de eventos catastróficos". (MANZINI, 2008. p. 39)
}

Segundo Manzini (2002), com foco na desmaterialização do consumo, os serviços ocupam lugar de destaque nas estratégias de desenvolvimento sustentável. Nesse contexto, o Sistema Produto-Serviço (PSS) configura-se como estratégia promissora às estratégias de negócios (UNEP, 
2004 apud MARTINS e SAMPAIO, 2006), uma vez que migra da comercialização de projeto de produtos para a comercialização de projetos de sistemas de bens e serviços de modo a satisfazer uma demanda do cliente (MANZINI e VEZZOLI, 2003).

Em síntese, PSS refere-se à importância de se agregar valor ao conjunto produto mais serviço como oferta de solução ao usuário (SAKAO et al., 2009) onde essa solução não é materializada em um único bem ou produto. Ao comercializar um sistema, além do fabricante adquirir maior propriedade sobre o produto (ALONSO, 2007), conquista também um maior contato com seu cliente - e isso faz com que o mesmo estabeleça uma relação de maior confiabilidade perante o sistema adquirido (BAINES et al, 2007), e consequentemente, o fabricante. Além disso, a partir do momento em que o fabricante tem propriedade direta sobre seu produto/sistema, o impacto ambiental é consequentemente, reduzido (BAINES, et al, 2007).

\section{Método de Pesquisa}

A abordagem adotada foi a de Design Science que, ao contrário das formas convencionais baseada em dedução ou indução, utiliza uma lógica abdutiva, de prescrição do futuro.

O conceito de Hevner et al (2004) sobre identificação de problemas enquanto uma etapa básica do processo, foi essencialmente empregado de modo a demonstrar a importância da pesquisa nas etapas iniciais do projeto. Complementarmente, os conceitos do Design Science Research Cycle de Simon (1996), foram fundamentais para guiar o projeto através dos ciclos de atividades que se repetem entre a pesquisa para construção de um artefato, avaliação e feedback para refinar o projeto. Este ciclo é repetido até que o projeto esteja completo, atingindo os objetivos através da inovação.

Para se atingir os resultados propostos, o procedimento metodológico utilizado iniciou-se com pesquisas primárias, etnográficas (Desktop Research) e de visitas técnicas (visita a condomínios residenciais da COHAB e visita à Home Center) na qual foi possível compreender o público-alvo, do ambiente a ser estudado e da existência de produtos no mercado. Após compilação de dados foi criada a persona do projeto, como ferramenta de segmentação de mercado. Na sequência foi usada a ferramenta Customer Journey para desenvolver a rotina da nossa persona e ver em que pontos chave nosso usuário poderia otimizar seu consumo de água. Dentro da rotina da persona, foi visto a atividade que seria a selecionada para trabalharmos o reuso da água cinza. Após análise do ambiente e das pesquisas sobre seus usuários, foi possível compreender a Persona e estudar, através de análises de soluções correlatas ou similares (Benchmark), quais seriam os problemas e as respectivas soluções.

Com o intuito de entender melhor a jornada do usuário, foi criado um system map da atividade de lavar roupas, com o qual foi possível identificar os stakeholders envolvidos nas etapas desse processo. Posteriormente, para finalizar a etapa informacional, foi realizada uma pesquisa de soluções similares (Benchmark), a fim de examinar as soluções de mercado direta ou indiretamente ligadas ao problema em questão.

Com o objetivo de complementar o direcionamento do projeto, foi utilizado a ferramenta de SDO (Sustainability Design-Orienting) para definir os requisitos e suas respectivas hierarquias dentro do projeto. Esta ferramenta foi importante para nortear as prioridades do projeto nos pilares econômicos, sustentáveis e sociais.

Foi dado início a etapa de conceituação do projeto através de uma atividade de desconstrução de similares e impulsionador de insights. No diagrama gerador de ideias (PSS + Idea 
Generation Tool) foi gerado insights sobre soluções em diversas partes do projeto, como ciclo de vida do produto, materiais, formas de uso, ciclo de vida e tecnologias que poderiam ser implementadas ao sistema. Como resultado dessa atividade, foi importantíssimo para o grupo desconstruir algumas ideias e se inspirar a partir de soluções inovadoras existentes.

A partir das ideias geradas e organizadas, foi necessário o uso da ferramenta de prototipação (Lego Serious Play) para testar as ideias e entender os touch points necessários para o sistema funcionar. Através desta visualização foi possível compreender dinâmica do serviço proposto, e foi possível melhorar as interações dentro do sistema.

Complementarmente, para finalizar a etapa de detalhamento do projeto, foi criado um Blueprint do sistema para demonstrar como o serviço irá funcionar. Através do blueprint foi visualizado e melhorado a interação entre os atores com o intuito de criar uma experiência que abrangesse os requisitos sociais, econômicos e sustentáveis do projeto.

\section{Resultados e Análise}

O presente artigo é um dos resultados da aplicação de métodos e processos utilizados para o "2nd Pillot Course Brazil" do projeto LeNsin 2 que ocorreu no mês de março de 2018, na UFPR. Ao total foram trinta horas-aula cujo programa contemplava abordagem teórica por parte de professores de diversas Universidades integrantes do projeto, bem como atividades práticas testadas diariamente na elaboração de projeto de PSS, solicitada como desafio por parte de cliente real.

Nesse período, as dimensões da sustentabilidade e da economia distribuída foram apresentadas e promoveram embasamento teórico subsidiário ao desenvolvimento de cada projeto. Através da determinação de métodos e processos e da efetiva aplicação de ferramentas do Design, foi possível desenhar o PSS proposto de maneira gradual e progressiva. Colocou-se em prática não apenas o desenho de soluções possíveis para problemas de ordem macro, como analisava-se, a cada novo recurso disponível, o contexto em que cada PSS seria inserido: o impacto que causaria ao usuário, à comunidade e à população.

Para o melhor entendimento do sistema (PSS), o quadro abaixo foi elaborado com o objetivo de mapear e concentrar os diversos stakeholders envolvidos, pontos de contato, diagnóstico de demandas e ainda soluções de acompanhamento para a eficiência do serviço.

\footnotetext{
${ }^{2}$ LeNsin: the Learning Network on Sustainability International. Projeto Financiado pelo programa ERASMUS+ Comissão Europeia voltado ao desenvolvimento curricular e difusão global do ensino sobre Sistemas Produto + Serviço Sustentáveis e Economia Distribuída. Disponível em: <http://www.lens-international.org>
} 


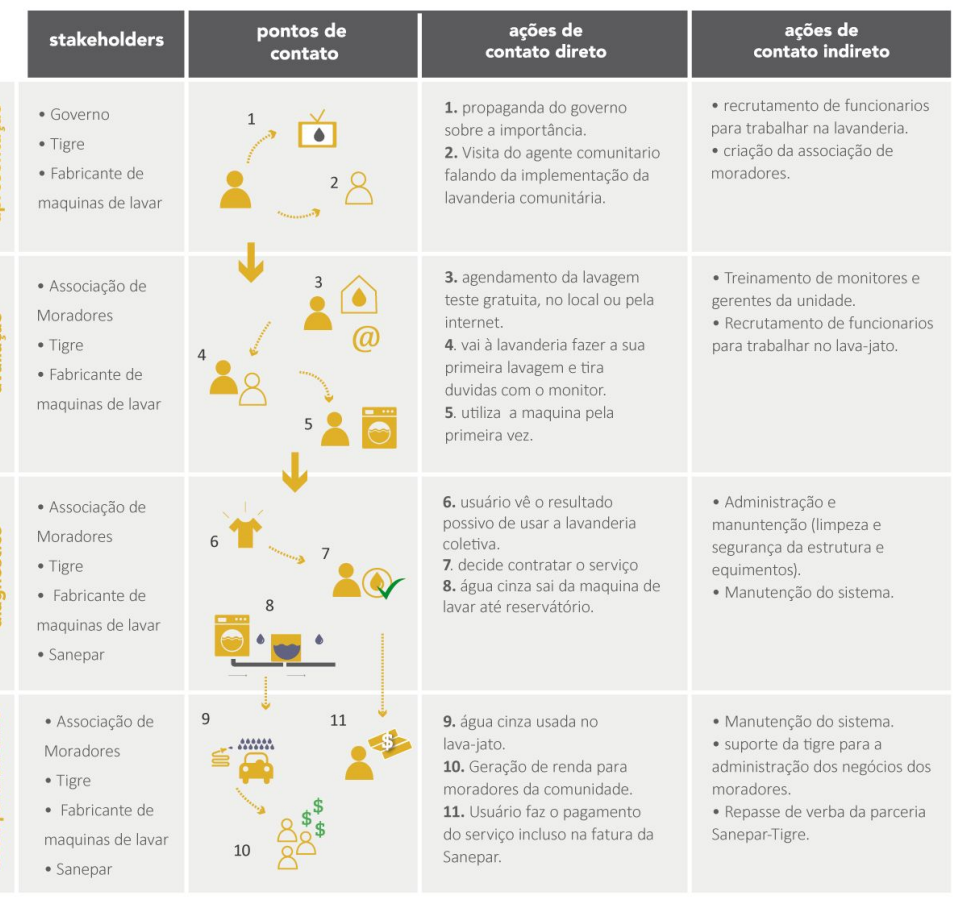

Fonte: os autores (2018)

O conceito do projeto e a definição do PSS poderiam, eventualmente, facilitar lacunas sobre viabilidade de execução. Visando diminuir hiatos entre necessidade e solução foram aplicados recursos de prototipação de produtos e serviços tais como: estudo arquitetônico e uso de mock-ups com peças de Lego; uso de heurísticas que traziam à tona prioridades a serem consideradas (Diagramas SDO) bem como a análise de informações de ordem econômico-financeira, necessárias ao modelo de negócios do PSS (Canvas Model).

Com os dados de pesquisas somados à dados informados pelo responsável técnico em visita a condomínios $C O H A B$, foi possível compreender o perfil da população de baixa renda e identificou-se na mulher, na faixa etária de 34 a 50 anos, protagonismo no maior número de contratos de financiamento da moradia.

Uma vez analisado o dimensionamento das residências ${ }^{3}$ (considerada unidade CT3) e os espaços destinados a realização de tarefas domésticas básicas (como cozinha e lavanderia) avaliou-se que a atividade principal desenvolvida neste perfil, bem como sua rotina diária de afazeres domésticos como o hábito de lavar roupas era significativa para identificação da necessidade de um PSS que promovesse melhoria na qualidade de vida. Essa melhoria está relacionada com a redução de tempo, de custos de água, luz e insumos destinados à atividade.

Identificada esta necessidade, projetou-se um PSS considerando-se a construção ou implantação de espaço itinerante, de metragem equivalente a duas unidades de moradia CT3 onde estariam dispostas máquinas de lavar roupa no sistema pay-per-use, ou seja: 0 usuário agendaria serviço e teria tempo para demais atividades. Os custos de luz água e insumos seriam proporcionais ao uso e compensados na taxa de condomínio mensal com possibilidades de benefícios ou abatimentos em valores para os moradores adeptos. Além de questões de o uso, e

\footnotetext{
${ }^{3}$ Considerados como referências os padrões de metragem: CT1 com 28,00 m²; CT2 com 34,00 m² e CT3 com 41,00m²
} 
tendo como unidade de satisfação a promoção do reuso econômico de águas cinzas, o espaço criado pelo PSS possibilitaria:

- Desenvolvimento de novos produtos, como tubulações, reservatórios para coleta e captação de águas residuais; de produtos inovadores, como eco detergentes, de menor impacto ambiental que produtos convencionais;

- Reutilização de águas cinzas em novos serviços, por exemplo na criação de um mini "Lava- Jato" que, além de reutilizar águas residuais das máquinas, ofereceria a redução de custos no consumo de água por alguns hábitos brasileiros como o hábito de lavar carros;

- $\quad$ Ampliação de áreas úteis da moradia com a realocação de espaço de lavanderia;

- Promoção de novos empregos locais na realização dos serviços derivados do PSS.

\section{Conclusão}

O período de experiência de participação no projeto LeNsin Brasil relatado neste presente documento, através do desenvolvimento de um projeto de sistema Produto+Serviço (PSS) demonstra as potencialidades de um pensamento sistêmico e holístico aplicado através de projetos no âmbito do design. É entendido que é necessário considerar que além de produtos que consigam suprir as novas demandas de infraestrutura, adotar práticas de sistemas que integrem produtos e serviços.

Foi visto que a metodologia de projeto sistêmico é muito inovadora e eficaz para encontrar soluções aplicáveis nos projetos de design sustentável. Em meio a tantos problemas ambientais que passamos hoje e vamos sentir no futuro, esta é uma abordagem fundamental para criar-se uma solução viável tanto para a sociedade, quanto para empresas e governo. Através de um consumo pontual e compartilhado de bens, um projeto de PSS trás soluções para viabilizar a desmaterialização necessária para manter os recursos naturais em equilíbrio. Então conclui-se por meio da experiência do LeNsin Brasil que o PSS foi uma solução eficaz para aprimorar o reuso de águas cinza.

\section{Referências}

ALONSO, M. P. Product service system: benefits and barriers. MSc Thesis. 2007. 105 p. School of Applied Sciences. Cranfield University. London, UK.2007.

BAINES et al. State-of-the-art in product-service systems. In: Proceedings of the Institution of Mechanical Engineers, Part B: Journal of Engineering Manufacture. Volume 221, Number 10 / 2007. Professional Engineering Publishing. London, UK: 2007.

GUIMARÃES, Beany; WAGNER, Ricardo, DSc. Design e Inovação Social. 2010.

HEVNER, Alan R. A three cycle view of design science research. Scandinavian journal of information systems, v. 19, n. 2, p. 4, 2007.

LeNsin: the Learning Network on Sustainability International. Projeto Financiado pelo programa ERASMUS+ Comissão Europeia voltado ao desenvolvimento curricular e difusão global do ensino sobre Sistemas Produto + Serviço Sustentáveis e Economia Distribuída. Disponível em:

$<$ http://www.lens-international.org>. 
MANZINI, Ezio. Design para a inovação social e sustentabilidade (LIVRO): Comunidades criativas, organizações colaborativas e novas redes projetuais. Editora E-papers, 2008.

MANZINI, E.; VEZZOLI, C. O desenvolvimento de produtos sustentáveis. Trad. Astrid de Carvalho. São Paulo: Ed. USP, 2002.

MANZINI, Ezio; VEZZOLI, Carlo. A strategic design approach to develop sustainable product service systems: examples taken from the 'environmentally friendly innovation' Italian prize. Journal of cleaner production, v. 11, n. 8, p. 851-857, 2003.

MARTINS, Suzana Barreto; SAMPAIO, Cláudio Pereira. Ecodesign e Design Sustentável-proposta de método para um workshop. In: Congresso brasileiro de pesquisa em design, P\&D Design. 2006.

NÚCLEO DE DESIGN E SUSTENTABILIDADE DA UFPR. O hábito de lavar roupas: uma agenda de inovação voltada para a atividade de "lavar roupa" no âmbito da Habitação de Interesse Social no Paraná. Curitiba, PR: Insight, 2014.

SAKAO, T.; SANDSTRÖM, G.; MATZEN, D. Framing research for service orientation of manufacturers through PSS approaches. Journal of Manufacture

SOTHE, Gabrielle C. in "Desinfecção de Águas Cinzas pelos Métodos de Cloração e Radiação Ultravioleta para fins de Reuso Não Potável".

SIMON, Herbert. The Sciences of the artificial, 3a Edição. 1996.

TUKKER, Arnold. 2004. Eight types of Product- Service-System: Eight ways to Sustainability? Experiences from Suspronet. TNO Institute of Strategy, Technology and Policy, The Netherlands.

SITE BB ÁGUA BRASIL. Dicas para Economizar Água. Disponível em:

<http://bbaguabrasil.com.br/dicas-para-economizar-agua >. Acesso em 02/04/2018.

Relatório Mundial das Nações Unidas sobre Desenvolvimento dos Recursos Hídricos 2016.

Disponível em: <http://unesdoc.unesco.org/images/0024/002440/244040por.pdf>. Acesso em:

02/04/2018. 